\title{
Nutritional Status of 3 Years to 18 Years of Age among the Khasi Children in the State of Meghalaya
}

\author{
Dr. Barikor C Warjri \\ Assistant professor Home Science Department, St Mary’s College, Shillong; Meghalaya
}

\begin{abstract}
The present study was conducted on West Khasi Hills District of the State of Meghalaya, India. Which is predominantly inhabited by the Khasis tribe which has a distinct characteristic of being a Matriarchal Society methodology: A cross sectional study of 495 males and557 females were included for this study, Three Anthropometric indices i.e. weight-for-age, height-for-age and BMI-forage are used for the assessment of the nutritional status. Finding: In case of weight, the prevalence of underweight for all sexes and ages was found to be $\mathbf{4 0 . 1 1 \%}$. The present findings indicate that there are no differences between the sexes with respect to the prevalence of underweight, although it was slightly higher in boys than in girls and about 52.28\% of children were stunted; Whereas in height there are no statistical differences between the sexes with respect to the prevalence of stunting, although it was higher in girls than in boys. However, the prevalence of stunting in the higher age group was much higher than that in the lower age group for both boys and girls, and the differences between the two major age groups are highly statistically significant in both boys $\left(\chi^{2}=19.86, D . F .=1, p<0.0001\right)$ and girls $\left(\chi^{2}=32.24, D . F .=1, p<0.0001\right)$. Conclusion: We may conclude that the present population is likely to be characterized by a very high prevalence of underweight and stunting with a high prevalence of wasting
\end{abstract}

Keywords: Weight, Height, BMI, Nutritional status

\section{Introduction}

Human growth is a regular process that is characterized by the changes in form, or size and function of an individual from conception till attainment of adulthood. It is believed that environmental factors, especially nutrition are of crucial importance in the expression of genetic potential of growth. In other words, although growth is subject to the genetic influence, it is considered that environmental factors, particularly nutrition, are very important in influencing human growth and development. Therefore physical growth of children is regarded as one of the best indicator of the nutritional status of a given population. In fact, the effects of under nutrition and over nutrition on growth and maturation of children are the major research problems in the field of nutrition and auxology

Nutritional status, on the other hand, is defined as a physical expression of the relationship between the nutrient intakes, or bio-availability of nutrients, and the physiological requirements of an individual (Brown, 1984). This physical expression of the relationship between nutrient intakes and physiological requirements of a person can be measured by a number of methods. Of the different methods, anthropometry is one that is generally used for measuring the nutritional status at both individual and population levels. Anthropometric measurements and indices like weight, height, mid upper arm circumference, skin fold thickness, weight-for-age, height-for-age, weight-for-height, body mass index, indices of upper arm circumference, etc., (WHO, 1963; Jelliffe, 1966; Frisancho, 1990) are used. The assessment of growth status of children's are generally carried out by comparing the attained height or weight for a given age with reliable growth references. For example, the U.S. National Center for Health Statistics (NCHS) growth references, now known as the Centers for Disease Control (CDC) growth references(Kuczmarski et al., 2000), and that of the WHO (2007) growth references are used widely for the assessment of growth and nutritional status of children in assessing their nutritional status

\section{Needs}

Recently, the National Family Health Surveys (NFHS-2 and NFHS-3) (IIPS \& Macro International, 2000, 2009) have revealed that Assam and Meghalaya are the two states with the highest prevalence of undernutrition in Northeast India, i.e., as indicated by anthropometric measurements and indices of the growth of children under 3 years of age. In Meghalaya, the high prevalence of undernutrition was also observed even in urban area for children aged 3-18 years (Mukherjee, 2002). It is likely that the prevalence of undernutrition will be higher in rural areas. Therefore, I undertake this study on growth and nutritional status of Khasi children aged 2-18 years in rural areas of the West Khasi Hills district, Meghalaya, in order to understand the nutritional status of these children.

\section{Review of Literature}

Martorell et al., (1994) has suggested that after 3 years of age, growth patterns of children in developing countries are similar to that of the international growth references. On the other hand, other authors have rejected this claim and argued the growth pattern of children in developing countries deviate significantly at the lower rate after 5 years of age. For example, Cameron (1992) has shown that the rural South African children followed near the $50^{\text {th }}$ percentile at 5 years of age, but thereafter growth rate was slower than the reference rate, and it was near the $3^{\text {rd }}$ percentile by the onset of adolescence. Similar findings can be observed in the growth studies in Northeast India (Begum and Choudhury, 1999; Khongsdier and Mukherjee, 2003). Earlier findings have, however, indicated that the affluent Indian girls are similar to the $50^{\text {th }}$ percentile of the NCHS growth references up to 12 years of age, thereafter the increments in height of 


\section{International Journal of Science and Research (IJSR) ISSN (Online): 2319-7064}

Index Copernicus Value (2013): 6.14 | Impact Factor (2014): 5.611

Indian girls were significantly lower than the NCHS references (Gopalan, 1996).

Choudhury (1979) studied the growth of Rabha boys of Assam aged 4 to 18 years and compared his findings with the Assamese caste boys. He found that the Rabha boys were taller and heavier than the Assamese caste boys during the early stages of growth. On the hand, the adult Rabhas were found to be the shorter than the caste and other population groups. Choudhury suggested that the population differences during the early stages of growth were mainly due to culture and food intake. The findings of this study are very interesting because other studies also indicated that children, not only from Northeast India (Begum and Choudhury, 1999; Mukherjee and Khongsdier, 2003a, 2003b) but also from other developing countries, are somewhat comparable to the $5^{\text {th }}$ or $10^{\text {th }}$ percentile of the international growth references, especially in the lower age groups. The implication is that growth retardation during the early stages of growth is mainly due to nutritional deprivation, or a failure in the expression of the genetic potential for growth (Gopalan, 1992).

In Northeast India, most of the growth studies were carried out in order to understand the population variation in growth patterns of children (Khongsdier and Ghosh, 1998). Very few growth studies have been carried out with a view to assessing the health and nutritional status of a population, especially in the state of Meghalaya (Khongsdier, 1996; Mukherjee, 2002).

\section{Method}

The data for the present study was collected from rural area of West khasi Hills by means of scarified random sampling in which the population size of the village is the main state of the sampling process. Viz, below 500 persons, 500-1000 persons, and above 1000 persons. The primary sampling units for each of the three state are villages to be random selected by using random numbers as given in to snedecor and cochran (1967), about 12 villages was randomly selected, taking in to consideration the population size according to the latest report given by the directorate of social welfare, government of Meghalaya.

Standard techniques of measurements described in Hoston (1946) Weiner and Lourie (1981) were followed while taking the Anthropometric measurement of children i.e. the height and weight.

For assessing the nutritional status children, we have adopted three anthropometric indices, that is, weight for age, height for age and body mass muscle (i.e. weight in height $\mathrm{kg} /$ height $^{2}$ in mts) for age, which one considered as good indicators of nutritional status.

These indices were derived both as Z - Scores and percentage of the international standards or references, i.e. growth reference of the U.91qNational Centre for Health

* Sensitive (NCHS) recently raised (Kucmalski Ct at, 2000) for which determining the sex differences according in different age groups. We have calculated the means and standard deviation the percentage of the NCHS growth references, for example, in the case of weight for age index; the percentage of the NCHS growth references was computed as follows.

Weight for age $(\%)=$ weight in $\mathrm{kg}$ of an individual at a given age/ (Medium value of the NCHS growth references of the same age) $\times 100$

For classifying the children into different grades of nutritional status, we have calculated the $\mathrm{Z}-$ Score of the individuals in relations to the NCHS growth references, using LMS method (Kuczmarski ct, at, 2000). This method was based on the median (M) the standard denation $\mathrm{S}$, and the power in the Box - Cox transformation (L). in order to obtain the $\mathrm{Z}$ score $(\mathrm{Z})$ or a given measurement, we used the following equation.

$$
\mathrm{Z}=\frac{(\mathrm{x} / \mathrm{m}) \mathrm{x} \mathrm{L})-1}{2: L S}
$$

Where $\mathrm{x}$ is the physical measurement (eg. Weight, height etc) and L, M and S are the values from the appropriate table corresponding to the age in months of the child the children were then categorized into three levels of nutritional status, following the cut - off points proposed by Viswera Roa (1996), which are as follows;

\author{
Normal $=-2$ to +2 of $Z-$ Score \\ Moderate $=-2$ to -3 of $Z-$ Score \\ Severe $=$ blow -3 of $Z-$ Score
}

\section{Result}

The major findings of the present study on nutritional status may be briefly summarized under the following points:

\section{Weight-for-age}

Weight-for-age, expressed as a Z-score of the individual weight relative to $\mathrm{CDC}$ growth references, is considered as one of the indicators of underweight. It is found that the overall mean Z-score of weight-for-age is significantly higher in girls than in boys $(\mathrm{t}=2.27, \mathrm{p}<0.05)$. As for the sex differences at different age groups, it is found that boys had a greater Z-score than girls only at 6 and 13 years of age. The girls are significantly greater in Z-score at 3,9 and 16 years onwards.

It is found that about $58.79 \%$ of boys and $60.86 \%$ of girls for all age groups are in the normal category ( -2 to +2 of $\mathrm{Z}$ scores) of nutritional status. The prevalence of moderate $(-2$ to -3 of Z-scores) and severe (below -3 of Z-scores) forms of underweight among boys is $33.13 \%$ and $8.08 \%$, respectively. Among girls, these frequencies are found to be $36.98 \%$ and $2.15 \%$, respectively. Thus, the prevalence of severe form of underweight is lower in girls, whereas the prevalence of moderate underweight is higher in girls than in boys. Nevertheless, the overall prevalence of underweight (below - 2 Z-score) was higher in boys (41.21\%) than girls $(39.14 \%)$. The sex differences in the prevalence of underweight are, however, not statistically significant $\left(\chi^{2}=\right.$ 0.47 , D.F. $=1, \mathrm{p}>0.05$ ). 


\section{International Journal of Science and Research (IJSR) \\ ISSN (Online): 2319-7064 \\ Index Copernicus Value (2013): 6.14 | Impact Factor (2014): 5.611}

As for age groups, it is found that in the age group 3-9 years, about $26.92 \%$ and $13.94 \%$ of boys, and $35.94 \%$ and $2.76 \%$ of girls are in the categories of moderate and severe forms of underweight, respectively. It is observed that girls had a lower prevalence of severe underweight, but were higher in the prevalence of moderate underweight. On the other hand, the overall prevalence of underweight is higher in boys $(40.87 \%)$ than in girls $(38.71 \%)$ in this age group, despite the absence of statistical significance $\left(\chi^{2}=0.21\right.$, D.F. $=1, p$ $>0.05)$.

In the older age group 10-18 years, the prevalence of moderate and severe forms of underweight among boys was found to be $37.63 \%$ and $3.83 \%$, respectively. These frequencies were respectively $37.65 \%$ and $1.76 \%$ among girls. It indicates that the sex differences are not clearly perceptible, although the prevalence of severe underweight was slightly lower in girls. Like in the age group 3-9 years, the overall prevalence of underweight (i.e., moderate plus severe forms) in this age group was also higher in boys $(41.46 \%)$ than in girls $(39.41 \%)$, although the difference is not statistically significant $\left(\chi^{2}=0.27\right.$, D.F. $\left.=1, \mathrm{p}>0.05\right)$.

Overall, the prevalence of underweight for all sexes and ages was found to be $40.11 \%$. The present findings indicate that there are no differences between the sexes with respect to the prevalence of underweight, although it was slightly higher in boys than in girls. Also, the differences between the two major age groups are not statistically significant, although it was slightly higher in the older age group.

\section{Height-for-age}

Height-for-age, expressed as a Z-score of the individual relative to $\mathrm{CDC}$ growth references, is considered in the present study as an indicator of short stature or stunting due to inadequate nutrition. It is observed that that the sex differences in mean z-scores of height-for-age are significant only during the adolescent period. The height-for-age Zscores were significantly higher in boys than in girls from 13 to 15 years of age. On the other hand, girls had greater Zscores from 17 to 18 years of age. These differences may be related to the differences in rates of growth concerning adolescent growth spurts.

It is found that about $49.29 \%, 43.23 \%$ and $7.47 \%$ of boys were in the categories of normal, moderate and severe forms of short stature or stunting as indicated by height-for-age. Among girls, these frequencies are $46.32 \%, 47.58 \%$ and $6.10 \%$, respectively. It is observed that the prevalence of moderate form of stunting was higher in girls, but they had a lower prevalence of the severe form of stunting as compared with boys. Overall, the prevalence of stunting (below $-2 \mathrm{Z}$ scores) was lower in boys $(50.71 \%)$ than in girls $(53.68 \%)$, despite the absence of statistical significant $\left(\chi^{2}=0.93\right.$, D.F. $=1, \mathrm{p}>0.05)$.

In the age group 3-9 years, about $31.73 \%$ and $7.21 \%$ of boys, and $29.95 \%$ and $7.37 \%$ of girls are in the categories of moderate and severe forms of stunting, respectively. The prevalence of the two forms of stunting in age group 3-9 years are by and large similar in both boys and girls, although the former were slightly higher in the prevalence of moderate stunting than the latter. The overall prevalence of stunting (i.e. moderate plus severe forms) was also slightly higher in boys $(38.94 \%)$ than in girls $(37.33 \%)$ in this age group $\left(\chi^{2}=0.12\right.$, D.F. $\left.=1, \mathrm{p}>0.05\right)$.

In the age group 10-18 years, the prevalence of moderate and severe forms of stunting among boys was found to be $51.57 \%$ and $7.66 \%$, respectively. These frequencies were respectively $58.82 \%$ and $5.29 \%$ among girls. The sex differences in the prevalence of the two forms of stunting are clearly perceptible. The prevalence of moderate stunting was higher in boys, whereas the prevalence of severe stunting was slightly lower in girls than boys. Nevertheless, the present analysis indicates that the overall prevalence of stunting (i.e., moderate plus severe forms) in the age group $10-18$ years was higher in girls $(64.11 \%)$ than in boys $(59.23 \%)$. However, this sex difference was not statistically significant $\left(\chi^{2}=1.57\right.$, D.F. $\left.=1, p>0.05\right)$

Overall, the present findings indicate that about $52.28 \%$ of children were stunted. There are no statistical differences between the sexes with respect to the prevalence of stunting, although it was higher in girls than in boys. However, the prevalence of stunting in the higher age group was much higher than that in the lower age group for both boys and girls, and the differences between the two major age groups are highly statistically significant in both boys $\left(\chi^{2}=19.86\right.$, D.F. $=1, \mathrm{p}<0.0001)$ and girls $\left(\chi^{2}=32.24\right.$, D.F. $=1, p$ $<0.0001)$. This difference between age groups may be associated with both biological and nutritional factors.

\section{BMI-for-age}

It is found that that the overall mean Z-score is slightly higher in girls than in boys. The sex differences with respect to different age groups are found to be significant only in the age group 9 years $(t=2.11, p<0.05)$. In age group 9 years, the girls are significantly greater in BMI-Z-score-for-age as compared with boys. Nevertheless, the overall sex differences in BMI Z-scores are not clearly perceptible.

As for the prevalence of wasting, it is found that about $87.27 \%, 7.07 \%$ and $3.23 \%$ of boys were in the categories of normal, moderate and severe forms of wasting. Among girls, these frequencies are $87.43 \%, 10.23 \%$ and $0.36 \%$, respectively. It indicates that the prevalence of moderate form of wasting was slightly higher in girls, whereas the prevalence of severe wasting was higher in boys. Nevertheless, the present study clearly indicates that the nutritional status as indicated by BMI-for-age is much better than that indicated by weight-for-age and height-for-age. This holds true for both boys and girls. The overall prevalence of wasting (below - 2 Z-scores) was by and large similar in both boys $(10.30 \%)$ and girls $(10.59 \%)$, giving a total incidence of about $10.46 \%$. It is also observed that overweight is also emerging, which was about $2.42 \%$ in boys and $1.97 \%$ in girls.

In the age group 3-9 years, about $8.65 \%$ and $7.21 \%$ of boys, and $11.06 \%$ and $0.92 \%$ of girls are in the categories of moderate and severe forms of wasting, respectively. Although the prevalence of moderate wasting is higher in girls, the overall prevalence of wasting (below - 2 Z-scores) is higher in boys (15.87\%) than in girls $(11.98 \%)$ in this age group, despite the absence of statistical significance $\left(\chi^{2}=\right.$

\section{Volume 5 Issue 1, January 2016}




\section{International Journal of Science and Research (IJSR) \\ ISSN (Online): 2319-7064 \\ Index Copernicus Value (2013): 6.14 | Impact Factor (2014): 5.611}

1.34 , D.F. $=1, \mathrm{p}>0.05)$. The prevalence of overweight was also fairly marked in this age group for both boys $(5.77 \%)$ and girls (5.07\%). However, the prevalence of overweight was absent in the older age group of 10-18 years. Thus, it these rates of overweight may be indicative of emerging childhood obesity, which is likely to form a double burden of undernutrition and overnutrition in the next decade or so as observed in other developing countries.

In the age group 10-18 years, it is found that the prevalence of moderate wasting was higher in girls $(9.71 \%)$ than in boys $(6.27 \%)$, although it was not statistically significant $\left(\chi^{2}\right.$ $=2.45$, D.F. $=1, \mathrm{p}>0.05)$. Nevertheless, the present findings indicate the absence of significant difference between the sexes by age groups, although the prevalence of overweight is likely to exist in the lower age group 3-9 years.

Overall, it is found that about $40.11 \%, 52.28 \%$ and $10.46 \%$ of the children in the present study were underweight, stunted and wasted, respectively. Following the classificatory criteria proposed by Gorstein et al., (1994), we may conclude that the present population is likely to be characterized by a very high prevalence of underweight and stunting with a high prevalence of wasting.

\section{Conclusion}

The present study has revealed the absence of statistical differences between the sexes in all the three forms of undernutrition. This observation is consistent with the earlier studies that gender differences in nutritional status are not the main problem among populations in Northeast India, especially among the tribal populations (Khongsdier et al., 2005). However, despite the absence of statistical differences, the prevalence of underweight was higher in boys than in girls, whereas the prevalence of stunting was higher in girls than in boys. It is generally believed that underweight is more related to environmental condition like inadequate nutrition and infection. Therefore, the higher prevalence of underweight in boys may have certain implications for the sex differences in responses to environmental factors. It has been suggested that girls are better "buffered" than boys against environmental factors like inadequate dietary intakes (Stinson, 1985; Bogin, 1999). This phenomenon has also been observed among the Lotha children of Nagaland (Tsopoe, 2003) and the Hmar children of Manipur (Khongsdier et al., 2005). Little is known about this problem in other Indian populations, thereby warranting more studies.

As for the question of higher prevalence of stunting in girls, it is difficult to give a proper explanation as it is also related to past history of growth status, in addition to genetic factors. It may be mentioned that the higher prevalence of stunting in girls was also observed among the Lotha children of Nagaland (Tsopoe, 2003). Thus, it is unlikely that the phenomenon is due to patrilineal or matrilineal system of the society. Instead, it may be related to the relevance of international growth references to populations in Northeast India. It is evident that the prevalence of stunting in the higher age group was much higher than that in the lower age group for both boys and girls, and the differences between the two major age groups are highly statistically significant in both boys. Therefore, it is likely that the applicability of the international growth references tends to be more irrelevant during and after adolescent period. This can also be observed with respect to the prevalence of stunting which is significantly related to age. We hope that future studies will shed much more light on this problem.

\section{Acknowledgement}

I would like to acknowledged my sincere thanks to Dr R.Khongsdier Professor Anthropology Department, North Eastern Hill University, for all his guidance and valuable suggestion

\section{References}

[1] Brown, K.H. 1984. Measurement of dietary intake. Popn. Dev. Rev. (Suppl.), 10: 69-91.

[2] Cameron, N. 1992. The monitoring of growth and nutritional status in South Africa. ., 21: 174-191.

[3] Hotton, F. A. 1946. Up from the Ape. New York: Macmillan Press.

[4] Jelliffe, D.B. 1966. Assessment of the nutritional status of the community. WHO Monograph Series No. 53. Geneva: WHO.

[5] Khongsdier, R. 1996. Assessment of growth and nutritional status: An anthropological perspective. Acta Med. Auxol., 28: 147-153.

[6] Khongsdier, R. 2002. Body mass index and morbidity in adult males of the War Khasi in Northeast India. Eur. J. Clin. Nutri., 56: 484-489.

[7] Khongsdier, R. and Ghosh, A.K. 1998. Human growth studies in Northeast India. In: North-East India. The human interference, edited by Raha, M.K. and Ghosh, A.K. New Delhi: Gyan Publication House.

[8] Khongsdier, R. and Mukerjee, N. 2003. Growth and nutritional status of the Khasi boys in Northeast India relating to exogamous marriages and socioeconomic classes. Am. J. Phys. Anthrop. (In press).

[9] Kuczmarski, R.J., Ogden, C.L., Grummer-Strawn, L.M., Flegal, K.M., Guo,S.S., Wei, R., Mei,Z., Curtin, L.R., Roche, A.F. and Johnson, C.L. 2000. Growth charts: United States. Advance Data from Vital and Health Statistics. Revised (Hyattsville, Maryland: National Center for Health Statistics).

[10] Martorell, R., Kettel Khan, L. and Schroeder, D.G. 1994. Reversibility of stunting: Epidemiological findings in children from developing countries. Eur. $J$. Clin. Nutr. (Suppl.), 48: 45-57.

[11] Mukherjee, N. 2002. Study on demography and growth pattern among the khasi children of Shillong, Meghalaya. Unpublished $\mathrm{PhD}$ thesis. Shillong: North Eastern Hill University.

[12] Stinson, S. 1985. Sex differences in environmental sensitivity during growth. Yearbook Phys. Anthrop., 28: 123-147.

[13] Visweswara Rao, K. (ed) 1996. Biostatistics. A Manual of Statistical Methods for Use in Health, Nutrition and Anthropology, $1^{\text {st }}$ edition. Jaypee Brothers. New Delhi: Medical Publishers (P) Ltd. 


\section{International Journal of Science and Research (IJSR) \\ ISSN (Online): 2319-7064}

Index Copernicus Value (2013): 6.14 | Impact Factor (2014): 5.611

[14] Weiner, J. S. and Lourie, J. A. 1981. Practical Human Biology. London: Academic Press.

\section{Author Profile}

Dr Barikor C Warjri is Post graduate on Family and Community Science, Research for Ph.D from Anthropology Department, Assistant Professor, Home science Department, St Mary's College, Shillong, India. 